\title{
Metodologias de intervençáo do terapeuta ocupacional em contexto escolar com crianças com Necessidades Educativas Especiais em Portugal
}

\author{
Andreia Sofia Nabiço Maia, Maria Raquel Rodrigues Santana, Susana Cristina Costa Pestana \\ Departamento de Saúde, Escola Superior de Saúde, Instituto Politécnico de Beja, Portugal.
}

\begin{abstract}
Resumo: Introdução: Os alunos com Necessidades Educativas Especiais devem ser inseridos em turmas regulares, recebendo todos os serviços educativos adequados que possibilitem o desenvolvimento de competências e capacidades dos mesmos. O sucesso da inclusão escolar depende da parceria entre os vários profissionais a intervir em contexto escolar. A importância do terapeuta ocupacional inserido numa equipe em contexto escolar já é reconhecida e valorizada pela comunidade, e é alvo de muitos estudos. Objetivo: Identificar as metodologias de intervenção utilizadas pelos terapeutas ocupacionais em Portugal, em contexto escolar, com crianças com Necessidades Educativas Especiais, de forma a aferir as metodologias mais comuns, bem como os aspectos relevantes que fazem parte do processo terapêutico. Método: Trata-se de uma investigação de caráter não experimental com base descritiva e transversal. Inicialmente, foi elaborado um questionário semiestruturado, de natureza quantitativa, que foi ministrado aos terapeutas ocupacionais que trabalham ou tenham trabalhado havia menos de três anos em contexto escolar. Resultados: A amostra é composta por 40 terapeutas ocupacionais, 37 são do sexo feminino e três são do sexo masculino. A maioria dos indivíduos $(77,5 \%)$ trabalha atualmente em contexto escolar. Os terapeutas ocupacionais intervêm principalmente com crianças, cujas idades estão compreendidas entre os 6 e os 18 anos. Conclusão: Verifica-se que as metodologias mais utilizadas pelos terapeutas ocupacionais são a atividade lúdica/brincar terapêutico e o treino de atividades da vida diária. A equitação com fins terapêuticos e a hipoterapia representam as metodologias menos utilizadas em contexto escolar, em que cada uma foi selecionada por $10 \%$ dos terapeutas.
\end{abstract}

Palavras-chave: Necessidades Educativas Especiais, Contexto Escolar, Metodologias de Intervenção, Terapia Ocupacional.

\section{Occupational therapists intervention methodologies in schools with children with Special Educational Needs in Portugal}

\begin{abstract}
Introduction: students with special educational needs should be inserted in regular classes, receiving all appropriate educational services allowing the development of skills and capabilities. The success of the school inclusion depends on the partnership between the various professionals in the school context. The insertion and occupational therapist's contribution in the area of education is the subject of many studies. The importance of a professional team in school context is already recognized and valued by the community. Objectives: the aim is to identify the intervention methodologies used by occupational therapists in school with children with special educational needs. In order to determine the most common methodologies as well as relevant aspects of the therapeutic process. Method: this is a non-experimental research with descriptive and cross-sectional basis. A semi-structured questionnaire was prepared initially, quantitative in nature that was taught to occupational therapists that work or have worked for less than 3 years in school context. Results: the sample is composed of 40 occupational therapists, 37 are female and 3 are male. The majority of individuals (77.5\%) currently works in school context. The occupational therapists involved mainly with children, aged between 6 and 18 years. Conclusion: the methodologies used by
\end{abstract}

Autor para correspondência: Maria Raquel Rodrigues Santana, Escola Superior de Saúde, Instituto Politécnico de Beja, Rua Pedro Soares, Campus do Instituto Politécnico de Beja, Apartado 6155, 7800-295, Beja, Portugal, e-mail: maria.santana@ipbeja.pt

Recebido em Jul. 6, 2015; $1^{\text {a }}$ Revisão em Out. 20, 2015; 2 Revisão em Nov. 9, 2015; Aceito em Fev. $20,2016$. 
the occupational therapists are playful activity/play therapy and the training activities of daily living. Riding for therapeutic purposes and the hippotherapy represent less widely used methodologies in school context, in that each was selected by $10 \%$ of therapists.

Keywords: Special Educational Needs, School Environment, Intervention Methodologies, Occupational Therapy.

\section{Introdução}

Considera-se um aluno com Necessidades Educativas Especiais (NEE) quando o mesmo, ao longo da sua escolarização, apresenta algum problema de aprendizagem que necessite de mais recursos educacionais e de atenção específica (CAMPOS, 2012). O conceito de NEE foi utilizado pela primeira vez no Relatório Warnock, em 1978, que denominou as crianças com NEE como sendo aquelas que precisam de ajuda educativa em algum momento do seu percurso escolar (IZQUIERDO, 2006). O objetivo da educação para os alunos com NEE é que estes superem as suas dificuldades, partindo do pressuposto de que cada criança tem o seu ritmo próprio de aprendizagem e que aprende de acordo com as suas capacidades. Para alcançar este objetivo, é importante que se elaborem programas educativos que se adequem às caraterísticas individuais de cada criança (MOTA, 2013). As NEEs englobam várias comunidades ou populaçóes que diferem entre si pelas suas características específicas, mas que, no fundo, se enquadram dentro de um mesmo grupo, o grupo de alunos com NEE (ROSA, 2010). O mesmo autor refere ainda que as dificuldades apresentadas por estes alunos podem ser de caráter permanente ou temporário. Este conceito confere, aos profissionais da educação, a possibilidade de classificar os alunos de acordo com o seu desempenho ou capacidade, permitindo a identificação das áreas que devem ser trabalhadas com cada criança e encontrar os recursos necessários para que isso seja possível (FERNÁNDEZ, 2009).

Em Portugal, a educação de alunos com NEE passou por diferentes paradigmas, incluindo a formação de escolas especiais, específicas para dar resposta às crianças com diversas deficiências, a implementação de turmas de apoio nas escolas convencionais para crianças com maiores dificuldades e ainda a inclusão das crianças com NEE nas turmas de ensino regular, de forma a apoiar a sua aprendizagem e integraçáo social, paradigma que persiste nas nossas escolas até hoje (RESENDE; FERREIRA; ROSA, 2010). Em um estudo de Trevisan e Barba (2012), no qual se pretende apontar as possibilidades de atuação da terapia ocupacional no processo de inclusão escolar de crianças com NEE, entende-se que a inclusão escolar,
[...] envolve um processo de reforma e de reestruturaçáo das escolas como um todo, desde a superação das barreiras arquitetónicas até, e principalmente, à superação das barreiras atitudinais [...] faz-se necessário um processo de interaçóesefetivas do indivíduo com as demais pessoas em uma sociedade preparada para recebê-lo, independentemente da complexidade de suas dificuldades (TREVISANA; BARBA, 2012, p. 90).

Segundo Ferreira (2011), o paradigma de inclusão escolar procura dar uma resposta para a exclusão escolar e propóe ações que garantam o acesso e a permanência do aluno com deficiência no ensino regular. O sucesso da inclusão de alunos com NEE na escola regular advém da possibilidade de se conseguirem progressos significativos desses alunos na sua escolaridade através da adequação das práticas pedagógicas. Atualmente, em Portugal, a educação de alunos com NEE é orientada, principalmente, pelo Decreto-Lei 3/2008 de 7 de Janeiro (PORTUGAL, 2008), no qual está referido que:

A educação especial tem por objetivos a inclusãoeducativa e social, o acesso e o sucesso educativo, a autonomia, a estabilidade emocional, bem como a promoçãoda igualdade de oportunidades, a preparaçáo para o prosseguimentode estudos ou para uma adequada preparação para a vida profissional e para uma transiçáo da escola parao emprego das crianças e dos jovens com necessidades educativas especiais [...].

Segundo Correia (2013), os referidos alunos devem ser inseridos em turmas regulares, recebendo todos os serviços educativos adequados, dando-lhes a oportunidade de conviver e partilhar experiências com outras crianças. A escola, para além de ser um local de crescimento e aprendizagem, representa um contexto em que as crianças criam amizades e começam a definir as suas personalidades. Considera-se ainda que é, nesta altura, que devem ser transmitidos os valores de sensibilização, para que ocorra uma aceitação da diferença por parte das restantes crianças (MOTA, 2013). Para além do que foi referido, o contexto escolar permite que a criança perceba que é parte integrante da sociedade, através da oportunidade que têm para 
experienciar diferentes atividades. Por sua vez, tais atividades promovem o desenvolvimento global da criança, a capacidade de ultrapassar dificuldades e o aumento de competências e capacidades (IDE; YAMAMOTO; SILVA, 2011).

Atualmente, o processo colaborativo necessário para o sucesso da inclusão escolar das crianças com NEE depende da parceria entre os vários profissionais a intervir em contexto escolar (SANCHES; TEODORO, 2007). Perante isto, pode aqui fazer-se referência ao estudo realizado por Bose e Hinojosa (2008), no qual é mencionado que, apesar de os terapeutas ocupacionais considerarem fundamental e valorizarem a colaboração entre os profissionais nas escolas, a construção dessa pareceria pode, por vezes, tornar-se um desafio (BOSE; HINOJOSA, 2008). Em Portugal, a inserção do terapeuta ocupacional no contexto escolar ocorre por meio de contratação de escola, isto é, nos agrupamentos de escola e escolas não agrupadas, existem concursos públicos para recrutamento de técnicos especializados (PORTUGAL, 2015), não existindo dados estatísticos que permitam aferir a percentagem destes técnicos nas escolas públicas portuguesas. Os agrupamentos de escolas (AE) são unidades organizacionais, dotados de órgãos próprios de administração e gestão, constituídos por estabelecimentos de educação pré-escolar e de um ou mais níveis e ciclos de ensino (PORTUGAL, 1998). Bebiano, Garcia e Santana (2008), demonstrando a sua intervenção numa unidade de apoio à multideficiência (UAM), na regiáo do Alentejo, em Portugal, referem que a educação de crianças com NEE de carácter permanente deve realizar-se, tanto quanto possível, em contexto educativo, representando a escola um local importante para a aquisição de aprendizagens fundamentais para a vida futura. Desta forma, evita-se que as crianças com NEE sejam institucionalizadas precocemente, permitindo um meio o mais normalizante possível, junto dos seus pares. As mesmas autoras defendem que, para que tal aconteça, é necessário o desenvolvimento de um trabalho em equipe, nomeadamente entre professores do ensino regular, professores de educação especial, psicólogos, terapeutas ocupacionais e outros técnicos (BEBIANO; GARCIA; SANTANA, 2008).

Por outro lado e à semelhança do que aconteceu na Europa, as escolas especiais, outrora formadas para dar resposta aos alunos com NEE, sofreram um decréscimo da frequência destes alunos, fruto da inclusão dos mesmos em contexto escolar, tendo sido obrigadas, assim, a reorientarem-se para a modalidade de "centro de recursos", atualmente designados como Centro de Recursos para a Inclusão (CRI)
(PORTUGAL, 2007). Este aspecto vai ao encontro a uma das orientações propostas na Declaração de Salamanca, que recomenda que as organizaçôes não governamentais (antigas escolas especiais designadas atualmente por entidades promotoras) devem colaborar com entidades oficiais através de respostas inclusivas às NEE (ORGANIZAÇÃO..., 1994). Tendo em conta o referido anteriormente, estas entidades promotoras prestam serviços principalmente nas seguintes vertentes: apoio à integração de alunos com NEE nas escolas e no ensino regular, apoio à transição da escola para a vida ativa e prestação de serviços de Intervenção Precoce na Infância (IPI) (PORTUGAL, 2007). Posto isto, podemos referir que, em Portugal, os AEs, em parceria com os CRI, desenvolvem atividades sustentadas num Plano de Ação em que estão definidos os apoios especializados a prestar pelo CRI, nos quais pode constar o terapeuta ocupacional (GOMES, 2013). Os perfis mais frequentes nas equipes técnicas do CRI são psicólogos, terapeutas ocupacionais e terapeutas da fala, sendo coerente com a tipologia dos apoios necessários aos alunos com NEE. No entanto, devido ao financiamento reduzido do Estado Português à entidade promotora, é notória a reduzida contratação em termos de horas das equipes técnicas dos CRI, face às necessidades sinalizadas pelos AE, com insuficiência em algumas áreas técnicas e em algumas zonas de Portugal (CENTRO..., 2015). Sempre que os apoios dos programas educativos individuais de cada aluno com NEE não possam ser prestados através dos recursos existentes nos $\mathrm{AE}$, são solicitados apoios às equipes do CRI que trabalham em articulaçáo com as escolas e famílias, e toda a comunidade educativa envolvente (PORTUGAL, 2007). Os técnicos especializados destas equipes atuam em diferentes níveis, junto das crianças e dos jovens com NEE, e das suas famílias, desde o diagnóstico a avaliação e intervenção educativa (GOMES, 2013; PORTUGAL, 2007). Segundo o Instituto Nacional para a Reabilitação (INR), "O objetivo geral dos CRI é apoiar a inclusão das crianças e jovens com deficiências e incapacidade, em parceria com as estruturas da comunidade [...]" (INSTITUTO..., 2011). Uma outra vertente de intervenção das entidades promotoras é a prestação de serviços de IPI (PORTUGAL, 2007). Também, aqui, os terapeutas ocupacionais fazem parte da equipe transdisciplinar, cujos objetivos primordiais de intervenção são apoiar, habilitar e capacitar as crianças e suas famílias. Tendo por base a intervenção centrada na família, o terapeuta ocupacional atua nos diversos contextos de desempenho ocupacional da criança, podendo realizar avaliaçóes e intervençôes 
no contexto familiar, escolar ou noutro contexto que se considere relevante (RODRIGUES, 2011). Com o objetivo de assegurar o direito a plena participação e inclusão social de todas as crianças de 0 a 6 anos, com base no Decreto-Lei 281/2009 de 6 de Outubro de 2009, foi criado o Sistema Nacional de Intervenção Precoce na Infância (SNIPI), que

[...] consiste num conjunto organizado de entidades institucionais e de natureza familiar, com vista a garantir condições de desenvolvimento das crianças com funções ou estruturas do corpo que limitam o crescimento pessoal, social, e a sua participação nas atividades típicas para a idade, bem como das crianças com risco grave de atraso no desenvolvimento (PORTUGAL, 2009).

Neste mesmo decreto, a IPI é definida como o conjunto de medidas de apoio integrado centrado na criança e na família, incluindo açôes de natureza preventiva e reabilitativa, designadamente no âmbito da educação, da saúde e da ação social (PORTUGAL, 2009).

O terapeuta ocupacional, bem como a restante equipe do CRI, atua em áreas-chave, nomeadamente, na execução de respostas educativas de educação especial; na realização direta de terapias; na implementação de estratégias para satisfazer necessidades educativas dos alunos; no desenvolvimento de açôes de apoio à família; na preparação dos jovens para transição para a vida adulta ou para integração em centros de atividades ocupacionais; na produção de materiais de apoio ao currículo em formatos acessíveis, e em outras açóes que se considerem necessárias para desenvolvimento do aluno com NEE (PORTUGAL, 2007). A Liga Portuguesa dos Deficientes Motores - Centro de Recursos para a Inclusáo, uma das entidades não governamentais promotoras de intervençáo terapêutica em contexto escolar, é dotada de uma equipe técnica que presta apoio no referido contexto, no qual está inserido o terapeuta ocupacional. Sáo desenvolvidas açóes de apoio à inclusão escolar de acordo com as necessidades educativas de cada aluno; dinamizaçáo das unidades especializadas; apoio na sala de aula; orientaçôes terapêuticas e pedagógicas periódicas, e intervenção terapêutica e pedagógica. Em termos terapêuticos, são desenvolvidas atividades de estimulação sensorial; promoção de atividades em meio aquático; hipoterapia; apoio nas AVDs, e elaboração de material pedagógico de apoio às aprendizagens escolares, bem como empréstimo de material aos estabelecimentos de ensino (NASCIMENTO, 2008). Afonso (2012) refere que a terapia ocupacional em contexto escolar permite que o aluno adquira maior capacidade de manipulaçáo e destreza, podendo ainda desenhar adaptações necessárias e efetuar o treino. Num estudo realizado acerca das perspetivas dos terapeutas ocupacionais enquanto elemento que desenvolve a atividade no contexto escolar português, foi aferido que estes técnicos se assumem como um recurso a quem os professores podem recorrer para os aconselhar quanto a estratégias de intervenção e promoção de autonomia. Pontualmente, é mencionada a adaptaçáo de contextos (GONÇALVES, 2012).

A realidade portuguesa permite-nos constatar que, no nível da IPI, o terapeuta ocupacional intervém no contexto natural da criança, sobretudo nos contextos familiar e escolar, não esquecendo o trabalho centrado nas prioridades da família (RODRIGUES, 2011). Na prestação do apoio direto à criança, são postas em prática açôes educativas e terapêuticas específicas, usando técnicas e teorias do brincar; técnicas e teorias do desenvolvimento motor, e técnicas de neurodesenvolvimento, nomeadamente Técnicas de Rood, Técnicas de Bobath, Técnicas de PNF e técnicas de integração sensorial. Compete ainda ao terapeuta ocupacional a orientação às famílias e a todos os intervenientes no processo terapêutico-pedagógico da criança, na adequação de posicionamentos; realização e adaptação de materiais e contextos; recomendar produtos e tecnologias de apoio; treinar AVDs e AVDIs (na escola, no lazer, no brincar); colaborar nos currículos adaptados de crianças com NEE, e implementar, através do brincar, atividades de motricidade fina, atividades sensoriopercetivas e atividades de estimulaçáo cognitiva (RODRIGUES, 2011). Também Correia (2011) defende que, na IPI, devem ser proporcionados programas terapêuticos específicos de terapia da fala ou terapia ocupacional, sendo que este último deve visar ao desenvolvimento de atividades motoras e sensoriais para estimular as habilidades de processamento sensorial, como a modulaçáo e a integração sensoriomotora (CORREIA, 2011). No estudo realizado por Mendes (2010), constata-se que a intervenção terapêutica centra-se na intervenção direta com crianças, no uso de tecnologias de apoio e nas modificaçôes ambientais para melhorar o desempenho ocupacional da criança.

Bebiano, Garcia e Santana (2008), em relação à intervençáo prestada pelo terapeuta ocupacional nas UAM, referem que são realizadas terapias individuais aplicando técnicas específicas, tendo em conta a patologia do aluno em causa. São valorizados os posicionamentos, a confeção e o uso de talas e as adaptaçóes do contexto para facilitar o desempenho ocupacional. Também são desenvolvidas atividades em grupo, com a colaboração de professores, que 
visam ao desenvolvimento motor. Faz parte, ainda, das funçóes do terapeuta ocupacional orientar as atividades de psicomotricidade na água e de equitação com fins terapêuticos, realizadas em contexto próprio, mas pertencentes às atividades desenvolvidas em meio escolar.

No Brasil, a inserção e o suporte de profissionais da área da saúde, especificamente do terapeuta ocupacional, na educação inclusiva, são incentivados desde a década de 1970 (LOURENÇO; CID, 2010). Entendeu-se que a educação era um dos campos de intervençáo da terapia ocupacional, não como uma ação clínica, mas sim dirigida a um trabalho a desenvolver coletivamente, visando, sobretudo, a integração e a inclusão de crianças no sistema de ensino regular (ROCHA, 2007; LOPES; SILVA, 2007). No estudo de Rocha e Deliberato (2012), é apontado que a ação do terapeuta ocupacional nas escolas tem por base um trabalho que deve ser desenvolvido em parceria com os educadores, os alunos, os pais e a comunidade, com o intuito de facilitar a participação das crianças no processo de aprendizagem (ROCHA; DELIBERATO, 2012). Também no estudo de Cardoso e Matsukura (2012), é referido que, no contexto escolar, os terapeutas ocupacionais assumem um papel fundamental na capacitação e na sensibilização de todos os envolvidos no processo de inclusão: família, escola e comunidade, uma vez que esta conduta é essencial para o sucesso da criança (CARDOSO; MATSUKURA, 2012; MUNGUBA, 2007). As autoras Paula e Baleoti (2011) defendem, no seu estudo, que a formação dos terapeutas ocupacionais permite-lhes atuar nos aspectos ergonômicos do ambiente escolar, podendo executar adaptaçóes físicas ou adaptaçóes de materiais e equipamentos já existentes (PAULA; BALEOTI, 2011). Para além disto, segundo o estudo de Trevisan e Barba (2012), os terapeutas ocupacionais podem aconselhar os familiares com o objetivo de construírem alguns recursos necessários para a criança (TREVISAN; BARBA, 2012). Por sua vez, os autores Ide, Yamamoto e Silva (2011) defendem, no seu estudo, que a participação do TO na comunidade escolar é direcionada à orientação dos atores sociais envolvidos no processo educativo do aluno, podendo acompanhá-lo individualmente numa sala de ensino regular e colaborar na avaliação periódica do desenvolvimento da criança (IDE; YAMAMOTO; SILVA, 2011).

É constatado que, cada vez mais, a intervenção do terapeuta ocupacional em contexto escolar é considerada importante, tendo em conta o número de técnicos que desenvolvem a sua atividade nesta área, fruto do aumento de vagas no nível dos AE, CRI e IP.
No entanto, não é possível aferir o número concreto de terapeutas ocupacionais a trabalhar em contexto escolar em Portugal, visto não existirem estatísticas nesta área. Também a literatura existente é fruto do desenvolvimento de trabalhos acadêmicos isolados, não sendo, portanto, possível aferir metodologias uniformes de intervenção do terapeuta ocupacional em contexto educativo. Perante a escassez de estudos em Portugal relativos à temática, surge o problema que dá origem à investigação: "Quais as metodologias de intervenção utilizadas pelos terapeutas ocupacionais em contexto escolar com as crianças com NEE?". Este problema surgiu decorrente da reflexão das possíveis metodologias de intervenção da terapia ocupacional e, uma vez que prática do terapeuta ocupacional em contexto escolar em Portugal já é comum, tornando-se fundamental evidenciá-la. Deste modo, justifica-se esta investigação, na medida em que dará a possibilidade de conhecer o trabalho realizado nas escolas de Portugal, através do levantamento das metodologias de intervençáo utilizadas pelos terapeutas ocupacionais no contexto escolar com crianças com NEE.

Considera-se que este estudo é uma mais-valia, uma vez que irá contribuir para o conhecimento e a prática da terapia ocupacional no contexto escolar, e, desta forma, alargar a literatura sobre a temática que está a ser estudada.

\section{Objetivos}

No presente artigo, pretende-se descrever as metodologias de intervenção utilizadas pelos terapeutas ocupacionais no contexto escolar em Portugal, com crianças com Necessidades Educativas Especiais.

Objetivos específicos:

1. Caracterizar os terapeutas ocupacionais que desenvolvem a sua prática clínica em contexto escolar;

2. Identificar o tipo de trabalho prestado no contexto escolar, a duração da intervenção, o tipo de acompanhamento prestado ao aluno e a periodicidade do mesmo;

3. Identificar as formaçôes específicas complementares dos terapeutas ocupacionais que desenvolvem a sua intervenção em contexto escolar;

4. Aferir quais as patologias mais comuns que são alvo de intervençáo por parte do terapeuta ocupacional, bem como a faixa etária da população intervencionada; 
5. Identificar quais os espaços físicos, dentro do contexto escolar, nos quais atua o terapeuta ocupacional;

6. Identificar metodologias de intervençáo usadas na abordagem do terapeuta ocupacional em contexto escolar.

\section{Método}

A presente pesquisa constitui-se de um estudo transversal de natureza descritiva, que ambiciona caracterizar o trabalho do terapeuta ocupacional em contexto escolar, envolvendo levantamento de campo de abordagem quantitativa e qualitativa, tendo em conta os objetivos específicos delineados anteriormente (SILVESTRE, 2007).

\subsection{Participantes}

Participaram, nesta pesquisa, os terapeutas ocupacionais de Portugal, que trabalham ou tenham trabalhado em contexto escolar com crianças com NEE. Como critérios de inclusão do estudo, foram considerados os terapeutas ocupacionais que trabalham nas escolas com crianças com NEE e os terapeutas ocupacionais que tivessem trabalhado nas escolas havia menos de 3 anos e que, então atualmente, já não trabalhavam. No processo de seleçâo dos participantes, não foram consideradas as características de idade e gênero. Os participantes foram selecionados através de um método de amostragem não probabilístico e por escolha racional (MAROCO, 2003).

\subsection{Instrumento}

O instrumento de investigação escolhido para a recolha de dados foi o questionário. No entanto, na ausência de um questionário standard referente ao tema em estudo, surgiu a necessidade de se elaborar um com vista a responder às particularidades da investigação. Optou-se pela construção de um questionário misto, com questôes abertas e questôes fechadas. No caso das questôes fechadas, foram utilizadas questóes dicotômicas, de escolha múltipla e questóes-filtro. As categorias utilizadas no questionário foram:

- Gênero (feminino/masculino);

- Idade (pergunta aberta);

- Área geográfica (norte/centro/sul/ilhas);
- Tempo de experiência profissional em contexto escolar (1-5 anos/6-10 anos/11-15 anos/mais de 15 anos);

- O terapeuta ocupacional trabalha atualmente em contexto escolar (sim/não);

- Carga horária de trabalho (número de horas de trabalho direto com crianças e número de horas de trabalho indireto);

- Qual o tipo de trabalho indireto realizado (pergunta aberta);

- O terapeuta ocupacional tem formação específica para trabalhar em contexto escolar (sim/náo);

- Quais as formaçóes específicas para trabalhar em contexto escolar (pergunta aberta);

- O TO tem formação complementar em Terapia Ocupacional (sim/não);

- Quais as formaçóes complementares em Terapia Ocupacional (pergunta aberta);

- Com que tipo de patologias o terapeuta ocupacional intervém (atrasos de desenvolvimento psicomotor/deficiência intelectual/dificuldades específicas de aprendizagem/paralisia cerebral/ perturbaçôes do espectro do autismo/síndromes genéticas/transtornos do déficit de atenção e hiperatividade/outros);

- Faixa etária da população;

- Espaço onde o terapeuta ocupacional desenvolve a intervenção (sala de ensino regular/sala individual/unidade de ensino estruturado/ unidade de apoio à multideficiência/espaços dentro da comunidade escolar - por exemplo ginásio/espaços exteriores ao da comunidade escolar - por exemplo hipódromo);

- Tipo de acompanhamento prestado (individual/ em grupo/ambos);

- Metodologias de intervenção utilizadas em grupo (pergunta aberta);

- Periodicidade de intervenção (1/2/3/4 vezes por semana/ diariamente);

- Duração das sessōes (pergunta aberta);

- Tipos de intervenção utilizados (Atividade lúdica, Brincar terapêutico/ Construção de materiais de baixo custo/ Equitação com fins terapêuticos/Hidroterapia/Hipoterapia/ Integração Sensorial/Processo de consultoria ${ }^{1 /}$ 
Processo de educaçáa ${ }^{2} /$ Snoezelen/Tecnologia Assistiva/Treino de Atividades da Vida Diária/ Outras).

Após término da construção do questionário, este foi enviado a três peritos para apreciação, sendo, posteriormente, realizadas as adequaçôes sugeridas, as quais envolveram trocas de terminologia, correçóes de erros ortográficos e inserção e/ou modificação de questôes. Como a disponibilização do questionário foi realizada por meio virtual, após as adequaçóes no instrumento, procedeu-se à aplicação do pré-teste de forma a verificar a eficácia e o valor do questionário, e para aferir a precisão do instrumento no molde virtual. Concluídas tais etapas, o questionário foi disponibilizado em plataforma digital em site específico pelo período de 15 dias. As respostas obtidas no questionário permitiram uma breve caracterização da população em estudo e possibilitaram uma visualização geral da atual intervenção do terapeuta ocupacional em contexto escolar.

\subsection{Coleta de dados}

Para contato com os participantes, foi divulgado o estudo e solicitada a participação no mesmo através de um mailing list de Terapia Ocupacional em Portugal, o que permitiu o contacto com todos os terapeutas ocupacionais de Portugal cadastrados nessa unidade.

Concomitantemente, foram realizados envios de convites de participação no estudo, pela pesquisadora, por meio de $e$-mails a contatos pessoais, bem como tal convite foi divulgado em redes sociais específicas da profissão.

A divulgação da mensagem-convite consistiu na explicitaçáo do objetivo da pesquisa, dos seus critérios de inclusão, assim como informava o link que permitia o acesso ao questionário, comunicando a data de sua disponibilização no sistema on-line. Observe-se que, ainda nesta mensagem, foi apresentado o consentimento informado que assegurou a confidencialidade.

\subsection{Análise de dados}

O tratamento dos dados recolhidos através dos questionários foi efetuado utilizando-se o recurso dos programas IBM SPSS Statistics versão $22 \mathrm{e} \mathrm{Microsoft}$ Office Excel 2007. Após o levantamento de campo, os resultados obtidos foram analisados por estatística descritiva, de natureza mista, através da análise das medidas de tendência central, de percentagens e frequências (componente quantitativa). $\mathrm{O}$ tratamento das respostas às questóes abertas foi feita com recurso à análise de conteúdo (componente qualitativa), em que se procedeu à categorização das respostas de três questôes (MOZZATO; GRZYBOVSKI, 2011; CAREGNATO; MUTTI, 2006).

Após a análise dos dados, os resultados foram discutidos à luz das evidências científicas utilizadas na introdução do trabalho. Inicialmente, serão apresentados os dados sociodemográficos dos inquiridos e, posteriormente, os dados relativos à intervenção dos terapeutas ocupacionais. Para finalizar, serão mencionadas as principais conclusôes assumidas durante a análise e a discussão dos resultados, assim como referidas as limitaçóes do estudo e fornecidas sugestôes para futuros estudos nesta área.

\section{Resultados e Discussão}

Dos 40 terapeutas ocupacionais que participaram no estudo, a grande maioria pertence ao sexo feminino ( $\mathrm{n}=37)$, e três são do sexo masculino, correspondendo a $92,5 \%$ e $7,5 \%$, respetivamente, do total de frequências. Assim, vemos que o gênero dos terapeutas que trabalham em contexto escolar com crianças com NEE é, habitualmente, o sexo feminino.

Em relação à idade dos terapeutas, vimos que esta varia entre um mínimo de 21 anos e um máximo de 49 anos. Com base no valor da mediana, podemos afirmar que $50 \%$ dos terapeutas têm entre 21 e 27 anos e $50 \%$ têm entre 27 e 49 anos.

Quanto à área geográfica em que exercem a profissão, observamos que, dos 40 terapeutas, 16 estão a trabalhar no Norte (40,0\%), 19 no Centro (47,5\%) e cinco no Sul $(12,5 \%)$ de Portugal, não havendo nenhum nas regiốes autônomas da Madeira e dos Açores. Assim, a região Centro do país é a área geográfica mais referida pelos inquiridos.

Relativamente ao tempo de experiência profissional em contexto escolar, a mesma varia entre um mínimo de um mês e um máximo de 25 anos, sendo que, em média, os terapeutas ocupacionais trabalhavam havia menos de cinco anos em contexto escolar. Uma análise dos quartis permitiu deduzir que 25\% trabalhavam havia menos de um ano (Q1); $25 \%$ entre 1 e 3,5 anos (Q2=Mediana); 25\% entre 3,5 anos e 6 anos (Q3), e $25 \%$ entre 6 anos e 25 anos. Havia, assim, $75 \%$ dos terapeutas com tempo de serviço inferior a 6 anos.

A maioria dos terapeutas $(77,5 \%)$ trabalha no corrente ano letivo em contexto escolar e $22,5 \%$, apesar de não trabalharem então atualmente naquele contexto, já o haviam feito nos últimos 3 anos anteriores à data do questionário. 
No que diz respeito às horas semanais de intervenção direta em contexto escolar, constata-se que estas variaram entre 2 horas e 40 horas semanais. A maioria dos terapeutas $(62,5 \%)$ trabalhava entre 27 e 40 horas em intervençáo direta, sendo que os terapeutas trabalhavam, em média, 26,1 horas em intervenção direta em contexto escolar.

No que diz respeito às horas semanais de trabalho indireto em contexto escolar, a maioria dos terapeutas trabalhava entre 0 e 7,2 horas indiretas. Utilizando-se os quartis, vemos que $25 \%$ faziam entre 0 e 2,3 horas de trabalho indireto, $25 \%$ entre 2,3 e 5 horas, $25 \%$ entre 5 e 8 horas e $25 \%$ entre 8 e 40 horas.

Dos terapeutas que então trabalhavam ou já haviam trabalhado horas indiretas em contexto escolar, 32 apresentaram um total de 115 respostas relativamente aos tipos de trabalho desenvolvidos durante esse período, correspondendo, em média, a 3,6 tipos por cada TO. Desta forma, a realizaçáo de "relatórios e registros" foi referida em 19 das 115 respostas, correspondendo a $68,8 \%$ dos terapeutas que realizavam trabalho indireto. Em segundo lugar, surge a "preparação de material para intervenção" que tinha sido utilizada por $59,4 \%$ dos terapeutas. Neste grupo de tipos de trabalho mais frequente, foram referidas também as "reuniôes de pais", "reuniōes de equipes" e "reuniôes de professores", com uma taxa de utilizaçáo de 53,1\%, 53,1\% e $50 \%$, respetivamente. Em relação aos tipos de trabalho menos utilizados, surgiram as "reuniôes interdisciplinares", "consultorias e pareceres técnicos" e "análise e cotação de instrumentos de avaliação", com taxas de utilização de 21,9\%, 21,9\% e 15,6\%, respetivamente. No que diz respeito ao tipo de trabalho indireto raramente referido, identificam-se as "formaçôes a professores/pais" e "participaçôes em projetos escolares", correspondendo somente a $4,4 \%$ do total dos tipos de trabalho referidos. Foi ainda referido por um dos participantes do estudo que:

O trabalho indireto [...] é insuficiente: não é possivel realizar os relatórios e as participaçôes nos PEIs (Programa Educativo Individual), não temos tempo para preparar material nem para reunir com pais e professores, nem para planear intervenção (sic).

Num estudo de Bose e Hinojosa (2008), cujo objetivo foi descrever as perspetivas dos terapeutas acerca das interaçóes com os professores nas escolas inclusivas, verificou-se que a falta de tempo para reuniōes é um fator condicionante à colaboração entre terapeutas e professores, e que os diálogos informais que ocorrem entre os mesmos são insuficientes para a criação e o planeamento de soluçóes. Nos resultados encontrados neste estudo, apenas um participante referiu isto como preocupante.

No que diz respeito ao número total de horas prestadas pelo terapeuta ocupacional em contexto escolar, este variou entre 2 horas até 40 horas, apresentando uma média de 32,6 horas.

Observamos que 24 (60\%) terapeutas consideraram ter formação específica para trabalhar com crianças com NEE em contexto escolar. Foi referido um total de 50 respostas relativas às formaçôes específicas, correspondendo, em média, a 2,1 formaçôes por cada terapeuta ocupacional. A formação específica mais frequente foi em Classificação Internacional de Funcionalidade (CIF), realizada por $66,7 \%$ dos terapeutas. Seguem-se as formaçôes gerais, realizadas por $50 \%$ dos terapeutas ocupacionais, em diferentes áreas de formação, tais como "autodeterminação de alunos com mais de 15 anos", "transição para a vida adulta", "dificuldades de aprendizagem", "intervenção na leitura e escrita", "perturbação do déficit de atenção", "sono", "mudança nas famílias", "desenvolvimento infantil", "a importância do brincar", "brinquedo adaptado", "inclusão escolar", "processo de referenciação para alunos com NEE", "NEE" e "iniciação à Língua Gestual Portuguesa". Posteriormente, destacam-se as formaçóes específicas em "integração sensorial" (25,0\%), "neurodesenvolvimento" (16,7\%), "autismo" (16,7\%) e "Snoezelen" (12,5\%). Por fim, as formaçôes específicas menos realizadas pelos terapeutas sáo: "hidroterapia", "hipoterapia", "bobath", "produtos de apoio" e "multideficiência", sendo cada uma dessas formaçóes realizada por $4,2 \%$ dos terapeutas.

Os $21(52,5 \%)$ terapeutas que referem ter formação complementar específica na área da Terapia Ocupacional apontaram um total de 28 respostas em relação aos tipos de formaçóes, correspondendo, em média, a 1,3 formação por cada terapeuta. A "Integração Sensorial" foi a formação mais mencionada, tendo sido realizada por $76,2 \%$ dos terapeutas. Seguidamente, aparece a formação em "Neurodesenvolvimento", realizada por 14,3\% dos terapeutas. Por último, foram mencionadas as formaçôes em "Protocolo PediaSuit", "Pós-graduação Membro Superior e Mão", "Saúde Mental”, "Terapia de Snoezelen", "Neuropsicologia de Intervenção", "Comportamentos Disfuncionais na Criança", "Produtos de Apoio" e "Hipoterapia", cada uma com uma taxa de realizaçáo de $4,8 \%$.

De acordo com o estudo de Rodrigues (2011), em que se relatam a experiência e a contribuição do TO na implementação de um Projeto de Intervenção Precoce, vemos que existem diferentes bases que direcionam a intervenção do terapeuta ocupacional, dentre as 
quais aparecem: Técnicas de Neurodesenvolvimento; Técnicas de Rood, Técnicas de Bobath, Técnicas de PNF e Técnicas de Integração Sensorial; Técnicas e Teorias do brincar; Teoria do Desenvolvimento Infantil, e Posicionamentos. Percebemos, entáo, que os resultados, aqui encontrados, vão ao encontro das respostas obtidas no nosso questionário, referentes às diferentes formaçôes que os terapeutas possuem.

$\mathrm{Na}$ questão relativa às patologias intervencionadas, os 40 terapeutas apresentaram um total de 234 respostas, correspondendo, assim, a uma média de 5,9 patologias intervencionadas por terapeuta, significando que a maioria intervém com a maior parte das sete patologias apresentadas (atrasos de desenvolvimento psicomotor; deficiência intelectual; dificuldades específicas de aprendizagem; paralisia cerebral; perturbações do espectro do autismo; síndromes genéticas; transtornos do déficit de atenção e hiperatividade). A patologia quase universalmente intervencionada é o grupo das perturbaçóes do espetro do autismo, enunciada por 39 dos inquiridos, correspondendo a uma taxa de intervenção de $97,5 \%$. Seguidamente, destacam-se os atrasos de desenvolvimento psicomotor $(92,5 \%)$, as deficiências intelectuais (85,5\%), as paralisias cerebrais (80\%), os transtornos de déficit de atenção e hiperatividade $(77,5 \%)$, as síndromes genéticas $(77,5 \%)$ e as dificuldades específicas de aprendizagem $(70,0 \%)$. Ainda foram referidas outras patologias por $5 \%$ dos terapeutas, nomeadamente outras síndromes e outras patologias sem especificação.

No que concerne à faixa etária, vemos que a maioria dos terapeutas faz intervençóes em crianças com idades compreendidas entre 6 e 18 anos, sendo que a maior percentagem incide na faixa etária entre os 6 e os 12 anos. Na faixa etária acima de 18 anos (19, 20 e 21 anos), ainda existem algumas intervençôes, sendo que as taxas variam entre $2,5 \%$ e $5 \%$.

Na questão relativa ao espaço em que a intervenção é desenvolvida, os 40 terapeutas identificaram um total de 161 respostas dentro das seis opçóes apresentadas, correspondendo a uma média de quatro espaços de intervenção por terapeuta. $\mathrm{O}$ espaço de intervenção utilizado pela quase totalidade dos terapeutas é a sala individual, tendo sido identificada por $92,5 \%$ do total de inquiridos. Em segundo lugar, destaca-se a unidade de apoio à multideficiência, utilizada por $75 \%$ dos inquiridos. A esta, seguem-se os espaços dentro da comunidade escolar $(72,5 \%)$, unidades de ensino estruturado (62,5\%), espaço exterior $\mathrm{da}$ comunidade escolar $(52,5 \%)$ e, por fim, a sala de ensino regular $(42,5 \%)$. Estes resultados vão de encontro ao estudo realizado por Gonçalves (2012), no qual foram apresentados os contextos em que habitualmente os terapeutas desenvolvem a sua intervenção na escola. De acordo com as respostas encontradas, concluiu-se que o espaço de intervenção varia de escola para escola, verificando-se que os terapeutas ocupacionais tanto podem trabalhar numa sala individual, como numa unidade de multideficiência, como dentro da sala de ensino regular, como também num refeitório (espaço dentro da comunidade escolar).

Relativamente ao acompanhamento prestado, podemos observar que $47,5 \%$ dos terapeutas somente fazem acompanhamento individual, que nenhum faz apenas acompanhamento em grupo e que a maioria $(52,5 \%)$ faz acompanhamento individual e em grupo.

No que diz respeito aos terapeutas que dizem realizar intervençôes individuais e em grupo, somente 13 apresentaram as metodologias específicas desenvolvidas em grupo, tendo estes reunido um total de 26 respostas. A metodologia mais utilizada nas intervençóes em grupo é o treino de competências sociais, utilizado por $38,5 \%$ dos terapeutas ocupacionais. A esta, seguem-se "sessôes de culinária" (30,8\%), "atividades da vida diária", "grupo de autonomia e funcionalidade", "participação social", "sessóes de movimento" e "hipoterapia", aplicadas por $15,4 \%$ dos terapeutas. As metodologias menos utilizadas são as "sessões de psicomotricidade" $(3,8 \%)$, "hidroterapia" (3,8\%), "atividades lúdicas" (3,8\%), "atividades funcionais" (3,8\%), "estimulação cognitiva" (3,8\%), "natação estruturada" $(3,8 \%)$ e "intervençôes transdisciplinares/familiares" (3,8\%).

Quanto à periodicidade de intervenção com cada criança, vemos que a maioria $(77,5 \%)$ dos terapeutas fazem intervençóes uma vez por semana. Dos restantes, $15,0 \%$ dos terapeutas realizam intervençôes bissemanais; $2,5 \%$, trissemanais, e $5,0 \%$, diárias.

Em relação à duração de cada sessão de intervenção, vemos que esta varia entre 30 minutos e 60 minutos, sendo que a duração média de cada sessão é de 44,4 minutos.

$\mathrm{Na}$ questão associada às metodologias de intervenção usadas na abordagem terapêutica, cujos resultados aparecem representados na Tabela 1, os 40 terapeutas enunciaram um total de 289 respostas, correspondendo, assim, a uma média de 7,2 metodologias usadas na abordagem terapêutica. As metodologias de intervenção mais utilizadas são a "atividade lúdica/brincar terapêutico" e o "treino de atividades da vida diária”, aplicados por $97,5 \% \mathrm{e}$ $92,5 \%$ dos terapeutas, respetivamente. Em seguida, destacam-se o "processo de educação" (82,5\%), a "integração sensorial" (72,5\%), o "processo de 
Tabela 1. Frequências das metodologias de intervenção usadas na abordagem terapêutica.

\begin{tabular}{lcc}
\hline \multicolumn{1}{c}{$\begin{array}{c}\text { Metodologias de intervenção usadas na abordagem } \\
\text { terapêutica }\end{array}$} & $\begin{array}{c}\text { F. Absolutas (n } \mathbf{n}_{\mathbf{k}} \text { ) } \\
\text { / F. Relativas (\%) }\end{array}$ & (\%) Linha \\
\hline Atividade lúdica/Brincar terapêutico & $39(13,5 \%)$ & 97,5 \\
Construção de materiais de baixo custo & $21(7,3 \%)$ & 52,5 \\
Equitação com fins terapêuticos & $4(1,4 \%)$ & 10,0 \\
Hidroterapia & $6(2,1 \%)$ & 15,0 \\
Hipoterapia & $4(1,4 \%)$ & 10,0 \\
Integração sensorial & $29(10,0 \%)$ & 72,5 \\
Processo de consultoria & $29(10,0 \%)$ & 72,5 \\
Processo de educação & $33(11,4 \%)$ & 82,5 \\
Snoezelen & $17(5,9 \%)$ & 42,5 \\
TA - Adaptação Ambiental e Doméstica & $15(5,2 \%)$ & 37,5 \\
TA - Mobilidade & $14(4,8 \%)$ & 35,0 \\
TA - Ortóteses e Próteses & $5(1,7 \%)$ & 12,5 \\
TA - Cadeira de Rodas e Sist. e Ad. Postural & $14(4,8 \%)$ & 35,0 \\
TA - Comunicação Alternativa e Aumentativa & $12(4,2 \%)$ & 30,0 \\
TA - Softwares Adaptados de Computador & $10(3,5 \%)$ & 25,0 \\
TA - Adaptação de Veículos & $0(0,0 \%)$ & 0,0 \\
Treino de Atividades da Vida Diária & $37(12,8 \%)$ & 92,5 \\
TOTAL & $\mathbf{2 8 9}(\mathbf{1 0 0 \% )}$ & $\mathbf{7 2 2 , 5}$ \\
N= 40; Moda= Ativ. Lúdica/Brincar Terapêutico; & & \\
N Média/TO = 7,3 Metodologias. & & \\
\hline
\end{tabular}

$\mathrm{n}_{\mathrm{k}}$ : frequência absoluta.

consultoria" (72,5\%) e a "construção de materiais de baixo custo" (52,5\%). Dentro das metodologias utilizadas pela minoria dos terapeutas, destaca-se a terapia "Snoezelen", aplicada em 42,5\% dos inquiridos.

As diferentes tecnologias assistivas, com exceção da adaptação de veículos, são aplicadas em taxas que variam entre $12,5 \%$ e $37,5 \%$, sendo a adaptação ambiental e doméstica (37,5\%), a mobilidade (35\%) e a cadeira de rodas, e o sistema de adequação postural (35\%), os mais utilizados. A "equitação com fins terapêuticos", a "hipoterapia" e a "hidroterapia" são utilizadas por $10 \%, 10 \%$ e $15 \%$ dos inquiridos, respectivamente. Depois de uma análise detalhada desta questão, observou-se, tal como referido anteriormente, que a metodologia de intervenção selecionada pela quase totalidade $(13,5 \%)$ dos terapeutas foi a "atividade lúdica/brincar terapêutico". Os autores Jurdi, Brunello e Honda (2004), citados por Trevisan e Barba (2012), defendem a importância do brincar identificando a atividade lúdica em grupo como uma intervenção que pode ser utilizada na escola, de forma a combater problemas do quotidiano que afetam a qualidade de aprendizagem e a convivência das crianças. $\mathrm{O}$ segundo tipo de intervenção mais referido é o treino de Atividades da Vida Diária (AVDs), utilizado por 37 dos terapeutas (12,8\%). A este, seguem-se o processo de educação $(11,4 \%)$, a integraçáo sensorial $(10,0 \%)$, o processo de consultadoria $(10,0 \%)$ e a construção de materiais de baixo custo (7,3\%). Num estudo realizado por Cardoso e Matsukura (2012), em que o objetivo se centrou na identificação e na caracterização das açóes desenvolvidas pela terapia ocupacional no processo de inclusão escolar de crianças com NEE no Estado de São Paulo, Brasil, os terapeutas ocupacionais identificaram como principais intervenções: orientação à família em relação à escola e à inclusão; orientaçóes gerais ao professor na escola regular; atividades realizadas em ambiente clínico/instituição para o desenvolvimento de competências cognitivo-motoras; orientaçóes gerais à escola de ensino regular; orientaçóes específicas sobre uso de tecnologia assistiva e/ou mobiliário, e treino de AVDs na clínica/instituição e orientação para essas atividades na escola regular. Neste estudo, não foram referidas como ações dos terapeutas ocupacionais a integração sensorial e a construção de materiais de baixo custo. No nosso estudo, também não foi identificada a estimulação das competências cognitivas como uma metodologia de intervenção. Assim, observamos que os dados obtidos no nosso estudo não estão totalmente de acordo com o estudo realizado por Cardoso e Matsukura (2012). Ainda relativamente ao processo de educação, também no estudo de Bose e Hinojosa (2008), já referido anteriormente, é assumido que o terapeuta ocupacional deve estar em constante interação com os professores e restantes agentes educativos, para que seja possivel a troca constante de informaçáo e conhecimento. 
Igualmente, no estudo efetuado por Gonçalves (2012), um dos participantes refere que um dos principais papéis do terapeuta ocupacional no contexto escolar assenta na passagem de estratégias aos professores e auxiliares. Relativamente às metodologias de intervenção menos utilizadas pelos terapeutas do nosso estudo, surgem o Snoezelen (5,9\%); seguem-se as diferentes tecnologias assistivas: adaptação ambiental e doméstica $(5,2 \%)$, mobilidade $(4,8 \%)$, cadeira de rodas e sistema de adequação postural $(4,8 \%)$, comunicaçáo alternativa e aumentativa $(4,2 \%)$, softwares adaptados de computador $(3,5 \%)$, ortóteses e próteses $(1,7 \%)$; hidroterapia $(2,1 \%)$, hipoterapia $(1,4 \%)$ e equitação com fins terapêuticos $(1,4 \%)$. No estudo realizado por Afonso (2012), em que se aborda a inclusão escolar do aluno com Paralisia Cerebral, é referido o terapeuta ocupacional como um técnico necessário à reabilitação do mesmo, sendo que este pode realizar adaptaçóes de material e alteraçôes de software e hardware. Também num estudo realizado por Mendes (2010), verifica-se que a intervenção terapêutica pode passar pelo uso da tecnologia assistiva, nomeadamente modificaçóes ambientais. De acordo com outros estudos, nomeadamente Ide, Yamamoto e Silva (2011), o terapeuta ocupacional pode intervir nas escolas de diferentes formas, tais como: adaptação de mobiliários e recursos pedagógicos; orientação e sensibilização da família, professores, funcionários, colegas de sala envolvidos com a criança com NEE; avaliaçáo da estrutura escolar; acompanhamento do aluno encaminhado para outra escola ou sala; auxiliar na avaliação periódica do desenvolvimento da criança, e aconselhar o professor quanto ao posicionamento do aluno e às mudanças posturais. Tanto no estudo de Rocha e Deliberato (2012) como no estudo de Paula e Baleoti (2011), é referida a contribuição significativa do terapeuta no que se refere a indicação e confeção de recursos adequados à criança e a orientaçóes sobre os mesmos. Contrariamente ao que se conseguiu observar no presente trabalho de investigação, nenhum dos estudos encontrados aponta ou sugere, como metodologias de intervenção dos terapeutas na escola, o Snoezelen, a hipoterapia, a hidroterapia e a equitação com fins terapêuticos.

\section{Conclusão}

Os resultados desta pesquisa permitiram atingir o objetivo do presente trabalho de investigação, uma vez que foi possível fazer um levantamento das metodologias de intervenção utilizadas em contexto escolar pelos terapeutas, com crianças com NEE em Portugal.
Ao refletir-se sobre o trabalho desenvolvido pelo terapeuta ocupacional no contexto escolar, percebe-se que as suas intervençôes podem ser diversas, dirigidas a diversas idades e a diferentes patologias. Considera-se que a combinação de metodologias de intervenção é fundamental no processo de educação das crianças com NEE, na medida em que lhes permite adquirir diversas competências.

Acreditamos que o que aqui foi exposto possibilitará não só uma visão geral do perfil dos terapeutas ocupacionais, como também o conhecimento da ação destes profissionais no contexto escolar.

Reconhecemos como crítico o fato de se ter dado um exemplo nas questóes relativas às formaçóes específicas na área de terapia ocupacional e para trabalhar em contexto escolar, uma vez que o exemplo exposto pode ter influenciado as respostas. É ainda de se referir que, na questão da zona geográfica, não foram obtidos os resultados esperados, isto é, esperava-se pelo menos um participante das ilhas; no entanto, tal não se verificou. Tendo em conta a nossa interpretação, podemos identificar a divulgação (tempo e forma) do questionário como o fator que desencadeou este desvio de resultados.

Como limitaçôes e desafios ao estudo, aponta-se, inicialmente, a ausência de um instrumento standardizado, que permitisse medir o que nos propusemos estudar. Desta forma, teve de proceder-se à construção de um questionário de acordo com o que era pretendido, o que implicou uma validação realizada por peritos, o que, consequentemente, prolongou o processo de investigação e a recolha dos dados, que se iniciaram mais tarde do que estava previsto. Outra das limitaçóes refere-se ao fato de não se ter reunido o número total de terapeutas ocupacionais que trabalham em contexto escolar, o que nos impossibilitou conhecer a representatividade da amostra recolhida. Também a escassez de estudos que abordem a temática dificultou a discussão dos resultados. A informação existente aponta, sobretudo, para a possibilidade de intervenção da terapia ocupacional na ação educativa, ou seja, o suporte teórico não é suficiente para poder comparar os resultados obtidos.

A administração do questionário em formato digital é apontada como um dos aspectos positivos, uma vez que permitiu que a recolha de dados fosse um processo mais ágil e econômico.

Este trabalho de investigação, para além de contribuir para a divulgação do trabalho desenvolvido pelos terapeutas em contexto escolar, permitiu também expandir as evidências científicas sobre esta temática, especificamente em Portugal, onde ainda existe escassez de estudos. 
Tendo em conta os resultados obtidos, sugere-se, para pesquisas futuras, um aprofundamento sobre as metodologias de intervenção utilizadas mediante as patologias intervencionadas, de modo a verificar se existe uma relaçáo entre as mesmas. Não menos importante seria a realização de um estudo longitudinal com o intuito de verificar a influência das metodologias de intervenção utilizadas nas competências e nas áreas de ocupação das crianças com NEE.

\section{Referências}

AFONSO, Â. M. O ensino e a paralisia cerebral. 2012. 89 f. Dissertação (Mestrado em Educação Especial) Escola Superior de Educação Almeida Garrett, Lisboa, 2012.

BEBIANO, M. F.; GARCIA, C.; SANTANA, M. R. Unidade de apoio à multideficiência - UAM. Aprender no alentejo. In: ENCONTRO REGIONAL DA EDUCAÇÃO, 4., 2008, Évora. Anais... Portugal: Universidade de Évora, 2008. p. 397-402.

BOSE, P.; HINOJOSA, J. Reported experiences from occupational therapist interacting with teachers in inclusive early childhood classrooms. American Journal of Occupational Therapy, Boston, v. 62, n. 3, p. 289-297, 2008.

CAMPOS, A. P. A inclusão de crianças com NEE em turmas do ensino regular: percepção de docentes, encarregados de educaçáo e representantes do conselho executivo. 2012. 131 f. Dissertação (Mestrado em Ciência da Educação) - Escola Superior de Educação João de Deus, Lisboa, 2012.

CARDOSO, P. T.; MATSUKURA, T. S. Práticas e perspectivas da Terapia Ocupacional na inclusão escolar. Revista de Terapia Ocupacional da Universidade de Sáo Paulo, São Paulo, v. 23, n. 1, p. 7-15, 2012.

CAREGNATO, R. C.; MUTTI, R. Pesquisa Qualitativa: Análise de discurso versus análise de conteúdo. Texto \& Contexto - Enfermagem, Florianópolis, v. 15, n. 4, p. 679-684, 2006.

CENTRO DE REABILITAÇÃO PROFISSIONAL DE GAIA - CRPG. Avaliação das políticas públicas - Inclusão de alunos com necessidades educativas especiais: o caso dos centros de recursos para a inclusão. Vila Nova de Gaia: CERCICA, 2015.

CORREIA, L. D. Inclusão e necessidades educativas especiais: um guia para educadores e professores. Porto: Porto Editora, 2013.

CORREIA, N. C. A importância da intervenção precoce para as crianças com autismo na perspectiva dos educadores e professores de educação especial. 2011. 129 f. Dissertação (Mestrado em Ciências da Educação) - Escola Superior de Educação Almeida Garrett, Lisboa, 2011.

FERNÁNDEZ, D. M. Aproximación a un estado del arte sobre las necesidades educativas especiales de los niños sordos en latinoamerica. 2009. $152 \mathrm{f}$. Trabajo de Grado (Licenciatura en Pedagogia Infantil) - Universidade de La Sabana, Faculdad de Educacion, Chía, Cundinamarca, 2009.

FERREIRA, D. C. A inclusão de crianças com nee no ensino regular. 2011. 187 f. Dissertação (Mestrado em Ciências da Educação) - Escola Superior de Educação Almeida Garrett, Lisboa, 2011.

GOMES, J. R. Centro de recursos para a inclusão na multideficiência: As Equipas. 2013. 115f. Dissertaçáo (Mestrado em Educação Especial) - Escola Superior de Educação do Porto, Portugal, 2013.

GONÇALVES, S. A. A perspectiva dos terapeutas ocupacionais sobre o seu trabalho enquanto elemento da equipa escolar. 2012. 81 f. Dissertação (Mestrado em Terapia Ocupacional) - Escola Superior de Tecnologia da Saúde do Porto, Porto, 2012.

IDE, M. G.; YAMAMOTO, B. T.; SILVA, C. C. Identificando possibilidades de atuação da Terapia Ocupacional na inclusão escolar. Cadernos de Terapia Ocupacional da UFSCar, São Carlos, v. 19, n. 3, p. 323-332, 2011.

INSTITUTO NACIONAL PARA A REABILITAÇÃO - INR. Centros de recursos para a inclusão - lista das acreditaçôes. Lisboa, 2011. Disponível em: <http://www.inr. $\mathrm{pt} /$ content/1/674/centros-de-recursos-para-inclusao-lista-das-acreditacoes>. Acesso em: 1 mar. 2014.

IZQUIERDO, T. M. Necessidades Educativas Especiais: a mudança pelo Relatório Warnock. 2006. 145f. Dissertação (Mestrado em Ciências da Educação) - Universidade de Aveiro, Aveiro, 2006.

LOPES, R. E.; SILVA, C. R. O Campo da educação e demandas para a Terapia Ocupacional no Brasil. Revista de Terapia Ocupacional da Universidade de São Paulo, São Paulo, v. 18, n. 3, p. 158-164, 2007.

LOURENÇO, G. F.; CID, M. F. Possibilidades de açáo do Terapeuta Ocupacional na Educação Infantil: congruência com a proposta da educaçáo inclusiva. Cadernos de Terapia Ocupacional da UFSCar, São Carlos, v. 18, n. 2, p. 169-179, 2010.

MAROCO, J. Análise estatística com utilização do SPSS. Lisboa: Ediçôes Sílabo, 2003.

MENDES, M. E. Avaliação da qualidade em intervenção precoce, práticas no distrito de portalegre. 2010.314f. Tese (Doutorado em Psicologia) - Universidade do Porto, Faculdade de Psicologia e de Ciências da Educação, 2010.

MOTA, N. G. A relação entre pares, no ensino básico, com alunos de necessidades educativas especiais integrados na turma. 2013. 150 f. Dissertação (Mestrado em Ciências da Educação) - Escola Superior de Educação São João de Deus, Lisboa, 2013.

MOZZATO, A. R.; GRZYBOVSKI, D. Análise de conteúdo como técnica de análise de dados qualitativos no campo da administração: potencial e desafios. Revista de Administração Contemporanea, Curitiba, v. 15, n. 4, p. 731-747, 2011. 
MUNGUBA, M. C. Inclusão escolar. In: CAVALCANTI, A.; GALVÃO, C. Terapia Ocupacional: fundamentação e prática. Rio de Janeiro: Guanabara Koogan, 2007. p. 519-525.

NASCIMENTO, A. T. Liga Portuguesa dos Deficientes Motores: de instituição de educação especial e reabilitação a centro de recursos; de centro de recursos a fundação. Estudo de caso de uma organização. 2008. 653 f. Tese (Doutorado em Estudos da Criança) - Universidade do Minho, Portugal, 2008.

ORGANIZAÇÃO DAS NAÇŌES UNIDAS PARA EDUCAÇÃO, CIÊNCIA E CULTURA - UNESCO. Declaração de Salamanca e Enquadramento da Acçâo: necessidades educativas especiais. Salamanca, 1994.

PAULA, A. F.; BALEOTI, L. R. Inclusão escolar do aluno com deficiência física: contribuiçôes da Terapia Ocupacional. Cadernos de Terapia Ocupacional da UFSCar, São Carlos, v. 19, n. 1, p. 53-69, 2011.

PORTUGAL. Decreto-Lei no 115 , de 4 de maio de 1998. Agrupamento de Escolas. Diário [da] República, Portugal, 4 maio 1998.

PORTUGAL. Ministério da Educação e Ciência. Direção-Geral da Educação - DGAE. Serviços de Educação Especial-Redes: reorientação de escolas especiais. Lisboa, 2007. Disponível em: <http://www.dge.mec.pt/servicos-de-educacao-especial-redes>. Acesso em: 27 set. 2015.

PORTUGAL. Decreto-Lei no 3/2008, de 7 de janeiro de 2008. Apoios especializados a prestar na educação pré-escolar e nos ensinos básico e secundário dos sectores público, particular e cooperativodiário da república, Diário [da] República, Portugal, 7 jan. 2008.

PORTUGAL. Decreto-Lei no 281, de 6 de outubro de 2009. Criação de um Sistema Nacional de Intervenção Precoce na Infância (SNIPI). Diário [da] República, Portugal, 6 out. 2009.

PORTUGAL. Ministério da Educação e Ciência. Direção-Geral da Administração Escolar - DGAE. Direção geral da Administração Escolar. Lisboa, 2015. Disponível em: <http://www.dgae.mec.pt/web/14650/132>. Acesso em: 27 set. 2015.

RESENDE, D. O.; FERREIRA, P. M.; ROSA, S. M. A Inclusão escolar de crianças e adolescentes com necessidades educacionais especiais: um olhar das mães. Cadernos de Terapia Ocupacional da UFSCar, São Carlos, v. 18, n. 2, p. 115-127, 2010.

ROCHA, A. N.; DELIBERATO, D. Atuação do terapeuta ocupacional no contexto escolar: o uso da tecnologia assistiva para o aluno com paralisia cerebral na educação infantil. Revista de Terapia Ocupacional da Universidade de São Paulo, São Paulo, v. 23, n. 3, p. 263-273, 2012.

ROCHA, E. F. A Terapia Ocupacional e as açōes na educação: aprofundando interfaces. Revista de Terapia Ocupacional da Universidade de São Paulo, São Paulo, v. 18, n. 3, p. 122-127, 2007.

RODRIGUES, P. J. A Terapia Ocupacional e a intervenção precoce na infância - de mãos dadas com as famílias. 2011. 65f. Monografia (Especialização em Terapia e Reabilitação) - Instituto Politécnico de Leiria, Portugal, 2011.

ROSA, F. M. Inclusão de alunos com necessidades educativas especiais no $2^{\circ}$ Ciclo do ensino básico: a perspectivas dos seus pares. 2010. 170 f. Dissertação (Mestrado em Educação Especial) - Escola Superior de Educação de Lisboa, Lisboa, 2010.

SANCHES, I.; TEODORO, A. Procurando Indicadores de Educação Inclusiva: as práticas dos professores de apoio educativo. Revista Portuguesa de Educação, Braga, v. 20, n. 2, p. 105-149, 2007.

SILVESTRE, A. L. Análise de dados e estatística descritiva. Lisboa: Escolar Editora, 2007

TREVISAN, J. G.; BARBA, P. C. S. D. Reflexões acerca da atuação do terapeuta ocupacional no processo de inclusão escolar de crianças com necessidades educacionais especiais. Cadernos de Terapia Ocupacional da UFSCar, São Carlos, v. 20, n. 1, p. 89-94, 2012.

\section{Contribuição dos Autores}

Andreia Sofia Nabiço Maia: Responsável pela concepçấo e redação do presente estudo. Maria Raquel Rodrigues Santana: Orientadora do estudo. Susana Cristina Costa Pestana: Coorientadora do estudo. Todas as autoras aprovaram a versão final do texto.

\section{Notas}

${ }^{1}$ Tipo de intervenção na qual os profissionais de terapia ocupacional usam seu conhecimento e experiência para colaborar com o cliente. Ex.: Aconselhar a família a como criar rotinas noturnas de pré-sono para seus filhos.

${ }^{2}$ Um processo de intervenção que envolve aquisição de conhecimento e informação sobre ocupação, saúde e participação, e que náo resulta em desempenho real da ocupação/atividade. Ex.: Instruir um professor de sala de aula acerca de estratégias de regulação sensorial. 